\title{
Phosphorylation of Actin-Depolymerizing Factor/Cofilin by LIM-Kinase Mediates Amyloid $\beta$-Induced Degeneration: A Potential Mechanism of Neuronal Dystrophy in Alzheimer's Disease
}

\author{
Lorena Heredia, ${ }^{1}$ Pablo Helguera, ${ }_{4}^{4}$ Soledad de Olmos, ${ }^{2}$ Gabriela Kedikian, ${ }^{1}$ Francisco Solá Vigo, ${ }^{1}$ Frank LaFerla, ${ }^{4}$ \\ Matthias Staufenbiel, ${ }^{5}$ José de Olmos, ${ }^{2}$ Jorge Busciglio, ${ }^{4}$ Alfredo Cáceres, ${ }^{3}$ and Alfredo Lorenzo ${ }^{1}$ \\ Laboratories of ${ }^{1}$ Experimental Neuropathology, ${ }^{2}$ Neuroanatomy, and ${ }^{3}$ Cell Biology, Instituto de Investigación Médica "Mercedes y Martín \\ Ferreyra"/Consejo Nacional de Investigaciones Científicas y Técnicas, 5000 Córdoba, Argentina, ${ }^{4}$ Department of Neurobiology and Behavior, University of \\ California, Irvine, California 92697-4550, and ${ }^{5}$ Novartis Institute for BioMedical Research Basel, Inc., CH-4002 Basel, Switzerland
}

\begin{abstract}
Deposition of fibrillar amyloid $\beta$ (fA $\beta$ ) plays a critical role in Alzheimer's disease (AD). We have shown recently that fA $\beta$-induced dystrophy requires the activation of focal adhesion proteins and the formation of aberrant focal adhesion structures, suggesting the activation of a mechanism of maladaptative plasticity in AD. Focal adhesions are actin-based structures that provide a structural link between the extracellular matrix and the cytoskeleton. To gain additional insight in the molecular mechanism of neuronal degeneration in $\mathrm{AD}$, here we explored the involvement of LIM kinase 1 (LIMK1), actin-depolymerizing factor (ADF), and cofilin in $\mathrm{A} \beta$-induced dystrophy. ADF/cofilin are actin-binding proteins that play a central role in actin filament dynamics, and LIMK1 is the kinase that phosphorylates and thereby inhibits ADF/cofilin. Our data indicate that treatment of hippocampal neurons with $\mathrm{fA} \beta$ increases the level of Ser3-phosphorylated ADF/cofilin and Thr508-phosphorylated LIMK1 (P-LIMK1), accompanied by a dramatic remodeling of actin filaments, neuritic dystrophy, and neuronal cell death. A synthetic peptide, S3 peptide, which acts as a specific competitor for ADF/cofilin phosphorylation by LIMK1, inhibited $\mathrm{fA} \beta$-induced $\mathrm{ADF} / \mathrm{cofilin}$ phosphorylation, preventing actin filament remodeling and neuronal degeneration, indicating the involvement of LIMK1 in A $\beta$-induced neuronal degeneration in vitro. Immunofluorescence analysis of AD brain showed a significant increase in the number of P-LIMK1-positive neurons in areas affected with AD pathology. P-LIMK1-positive neurons also showed early signs of $\mathrm{AD}$ pathology, such as intracellular $\mathrm{A} \beta$ and pretangle phosphorylated tau. Thus, LIMK1 activation may play a key role in $\mathrm{AD}$ pathology.
\end{abstract}

Key words: amyloid $\beta$; $\beta$; LIMK1; ADF/cofilin; Alzheimer's disease; dystrophic neuritis; neuronal neurodegeneration

\section{Introduction}

Dystrophic neurites are markedly distorted axons and dendrites that characterize Alzheimer's pathology (Benzing et al., 1993), playing an important role in cognitive impairment in the disease (McKee et al., 1991; Spires and Hyman, 2004). Dystrophic neurites typically associate with senile plaques, the hallmark lesions of Alzheimer's disease (AD). Amyloid $\beta(\mathrm{A} \beta)$, a 40-43 amino acid derivative of the metabolism of amyloid $\beta$ precursor protein

\footnotetext{
Received July 21, 2005; revised April 28, 2006; accepted April 30, 2006.

This work was supported by Agencia Nacional de Promoción Científica y Technológica Grant PICT 5-14291 and by grants from Fundación Antorchas (A.L.), the Howard Hughes Medical Institute International Research Scholar Program (A.C.), the Alzheimer Association (J.B.), and a fellowship from Fundación Interior Argentina (L.H.). A.L., J.d.O., and A.C. are career members of Consejo Nacional de Investigaciones Científicas y Técnicas. A.L. is an Associate Researcher of the Center for Cell Regulation and Pathology (Grant 13980001), Chile. We thank Dr. James Bamburg for kindly providing antibodies to phosphorylated ADF.

Correspondence should be addressed to Dr. Alfredo Lorenzo, Laboratory of Experimental Neuropathology, Instituto de Investigación Médica "Mercedes y Martín Ferreyra"/Consejo Nacional de Investigaciones Científicas y Técnicas, Casilla de Correo 389, 5000 Córdoba, Argentina. E-mail: alorenzo@immf.uncor.edu.

D0I:10.1523/JNEUROSC1.5567-05.2006

Copyright $\odot 2006$ Society for Neuroscience $\quad$ 0270-6474/06/266533-10\$15.00/0
}

$(\mathrm{A} \beta \mathrm{PP})$, is the main constituent of senile plaques (Hardy and Selkoe, 2002). A $\beta$ aggregation is required for senile plaque formation and renders A $\beta$ neurotoxic (Pike et al., 1991; Lorenzo and Yankner, 1994; Lambert et al., 1998). A $\beta$ neurotoxicity induces neuronal dystrophy characterized by aberrant neuritic morphology, sprouting, and breakdown (Busciglio et al., 1992; Grace et al., 2002). Much effort was devoted to understand the mechanism that links $\mathrm{A} \beta$ deposition to tau pathology as an attempt to define the events that lead to neurofibrillary tangle formation in $\mathrm{AD}$ (Busciglio et al., 1995; Lee et al., 2000; Götz et al., 2001; Oddo et al., 2003), whereas less attention was put on upstream events that may trigger the dystrophic process. We have shown recently that such early events may include the clustering of $\mathrm{A} \beta \mathrm{PP}$ and integrin receptors at the cell surface around $A \beta$ fibrils, the activation of focal adhesion proteins, and the formation of aberrant focal adhesion structures (Grace and Busciglio, 2003; Heredia et al., 2004), suggesting that $A \beta$ deposition triggers a pathological mechanism of plasticity leading to neuronal dystrophy.

Focal adhesions provide a structural link between the extracellular matrix and the actin cytoskeleton. Actin filaments are 
essential components of the adhesive complex, and its dynamic reorganization provides the initial force to adapt neuronal morphology to its surrounding. Actin-depolymerizing factor (ADF) and cofilin are actin-binding proteins that critically control actin filament dynamics and reorganization by severing and depolymerizing actin filaments (Bamburg and Wiggan, 2002). LIM kinase 1 (LIMK1) phosphorylates and thereby inhibits ADF/cofilin (Arber et al., 1998). LIMK1 is widely expressed in tissues, including the nervous system (Proschel et al., 1995; Foletta et al., 2004), and its activity modulates neuritogenesis and synaptic plasticity (Meng et al., 2002; Endo et al., 2003; Rosso et al., 2004). LIMK1 is a key downstream effector of the Rho family of small GTPases and is activated by phosphorylation on Thr508 by Rho kinase ROCK, or by Rac-Cdc42 p21-activated kinase (PAK) (Edwards et al., 1999). Recent observations showed that a multiprotein complex containing LIMK1 and its kinase activator PAK can be recruited into the focal adhesion complex by p95PKL-mediated binding to Paxillin (Turner, 2000; Chen et al., 2005), raising the possibility that LIMK1 may be required for $A \beta$-induced actin filament remodeling in focal adhesions. To gain additional insight into the molecular mechanism that leads to neuronal dystrophy in $\mathrm{AD}$, we analyzed the involvement of LIMK1, ADF/ cofilin, and actin cytoskeleton in $\mathrm{A} \beta$-induced neuritic dystrophy. Our results indicate that $\mathrm{A} \beta$ degeneration requires the activation of LIMK1 and the rearrangement of actin cytoskeleton; in addition, high levels of Thr-508-phosphorylated LIMK-1 (P-LIMK1) were found in $\mathrm{AD}$ brain, suggesting the involvement of LIMK1 in $\mathrm{AD}$ pathology.

\section{Materials and Methods}

Human tissue, histological processing, and immunofluorescence. Human brain tissue samples from the entorhinal cortex of seven neuropathologically confirmed $\mathrm{AD}$ cases and three age-matched controls obtained from the Institute for Brain Aging and Dementia Tissue Repositories at the University of California, Irvine, were included in this study. Tissue sections from human brain were processed for immunofluorescence as described previously (Head et al., 2002). For specimen examination and imaging, an Axiovert 200 inverted microscope (Zeiss, Jena, Germany) was used. Fluorescent images were captured with a digital camera (Zeiss) and processed using AxioVision (Zeiss) as described previously (Helguera et al., 2005).

The following antibodies were used: polyclonal anti-P-LIMK (1:50; Cell Signaling Technology, Beverly, MA), monoclonal anti-human PHF-1 Tau (1:500; Pierce, Rockford, IL), monoclonal anti-A $\beta$ clone 6F/3D (1:500; Dako, Glostrup, Denmark), monoclonal anti-A $\beta$ clone 6E10 (1:100; Senetek, Napa, CA), and mouse monoclonal anti-A $\beta 42$, which specifically recognizes the $\mathrm{C}$ terminus of $\mathrm{A} \beta \mathrm{x}-42$ (Busciglio et al., 2002; Helguera et al., 2005).

Neuronal cultures. Rat cortical and hippocampal cultures were established from embryonic day 18-19 fetuses as described previously (Lorenzo and Yankner, 1994). High-density cultures $\left(2500 \mathrm{cells} / \mathrm{mm}^{2}\right.$ ) were used for biochemical analysis; low-density cultures $\left(100 \mathrm{cells} / \mathrm{mm}^{2}\right)$ were used for immunocytochemistry. The cells were plated in DMEM (Invitrogen, Gaithersburg, MD) plus 10\% horse serum (Hyclone, Logan, UT) on poly-L-lysine ( $1 \mathrm{mg} / \mathrm{ml})$-coated dishes or coverslips; after $2 \mathrm{~h}$, the medium was replaced with glia-conditioned DMEM plus N2 and B27 supplements (Invitrogen) medium. The cultures were maintained at $37^{\circ} \mathrm{C}$ in a $5 \% \mathrm{CO}_{2}$ humidified atmosphere.

Peptides and treatments. Synthetic A $\beta 1-40$ (Biopeptide, San Diego, CA) was dissolved in sterile double-distilled water to a concentration of 1 $\mathrm{mm}$, incubated for $3 \mathrm{~d}$ at $37^{\circ} \mathrm{C}$, and further diluted in PBS to $0.5 \mathrm{~mm}$ to allow fibril formation. A $\beta 25-35$ was dissolved in sterile double-distilled water to a concentration of $1 \mathrm{~mm}$, further diluted in PBS to $0.5 \mathrm{~mm}$, and incubated for $1 \mathrm{~d}$ at $37^{\circ} \mathrm{C}$. These $\mathrm{A} \beta$ preparations are mainly composed of amyloid fibrils, as shown by electron microscopy and Congo red birefringence (Lorenzo and Yankner, 1994). Nonfibrillar, soluble A $\beta$ (sA $\beta$ ) peptides were added to the medium without preincubation. S3 peptide (Biopeptide) was dissolved in sterile double-distilled water to a concentration of $2.5 \mathrm{~mm}$ and added to the cultures to the indicated final concentrations.

Western blot. Cultures were harvested in radioimmunoprecipitation assay buffer (1\% Triton X-100, $1 \%$ sodium deoxycholate, $0.1 \%$ SDS, 0.15 $\mathrm{M} \mathrm{NaCl}$, and $0.05 \mathrm{~m}$ Tris-HCl, $\mathrm{pH}$ 7.2) with protease inhibitors (Complete mini; Roche, Indianapolis, IN) at $4^{\circ} \mathrm{C}$. The cell homogenates were then diluted in Laemmli sample buffer and incubated at $95^{\circ} \mathrm{C}$ for $5 \mathrm{~min}$. Protein homogenates were separated on standard 8 or $12 \%$ polyacrylamide gels and transferred to polyvinylidene difluoride membranes. After blocking with $5 \%$ milk or $5 \%$ bovine serum albumin in PBS with $0.05 \%$ Tween 20 , the membranes were incubated overnight at $4^{\circ} \mathrm{C}$ with primary antibodies, followed by an HRP-conjugated secondary antibody (Jackson ImmunoResearch, West Grove, PA). The following primary antibodies were used: monoclonal anti-tubulin $\beta$ III (1:1000; Chemicon, Temecula, CA), polyclonal anti-Ser3 phosphorylated cofilin 4317 (1:2000; kindly provided by Dr. J. Bamburg, Colorado State University, Fort Collins, CO), polyclonal anti-P-LIMK (1:100; Cell Signaling Technology), a polyclonal antibody against LIMK1 (1:100; Santa Cruz Biotechnology, Santa Cruz, CA), and a polyclonal antibody against nonphosphorylated cofilin (1:100; Santa Cruz Biotechnology). Protein bands were visualized by chemiluminiscence. Semiquantitative analysis was performed using Scion Image software; values were expressed as percentage of control samples. Each experimental condition was performed in triplicate, and experiments were replicated two to five separate times.

Immunofluorescence. Cell cultures were fixed in $4 \%$ paraformaldehyde and $0.12 \mathrm{M}$ sucrose in PBS for $30 \mathrm{~min}$ at $37^{\circ} \mathrm{C}$, permeabilized for $5-7 \mathrm{~min}$ with $0.2 \%$ Triton X-100 in PBS, and blocked for $40 \mathrm{~min}$ in $5 \%$ normal horse serum. The cells were then incubated for $2 \mathrm{~h}$ at room temperature with primary antibodies, followed by incubation with Alexa-conjugated secondary antibodies (Invitrogen, Eugene, OR). The following antibodies were used: monoclonal anti-neuronal-specific tubulin $\beta$ III (1:500; Chemicon), monoclonal anti-A $\beta$ clone 6F/3D (1:500; Dako), polyclonal anti-Ser3 phosphorylated cofilin 4321 (1:200; kindly provided by Dr. J. Bamburg), monoclonal anti-microtubule-associated protein 2 (MAP2) clone AP20 (1:200; Sigma, St. Louis, MO), and polyclonal anti-P-LIMK (1:200; Cell Signaling Technology). Actin filaments were labeled with rhodamine-phalloidin (Invitrogen). To label A $\beta$ fibrils, a mixture (10:1 ratio) of unlabeled $A \beta 1-40$ and biotinylated $A \beta 1-40$ were used; after fixation, the cultures were incubated with Neutravidin Alexa350 (Invitrogen). To assess fluorescence intensity, nonsaturating digital images were acquired from control and $A \beta$-treated cultures under the same conditions using a Zeiss Pascal confocal microscope. Image scans were performed directly pixel by pixel within the cell body and neurites of random neurons using a MetaMorph/Metafluor Image Processor (Universal Imaging, West Chester, PA) controlled by a host IBM-AT computer.

Expression plasmids and transfections. Expression plasmids for fulllength wild-type LIMK1 and the LIMK1-kinase dead mutant were described previously (Rosso et al., 2004). Transient transfection of cultured neurons was performed in rat hippocampal cultures that were grown in DMEM plus N2 and B27 supplements (Invitrogen) in a 96-multiwell culture plate at high density (80,000 cells/well). Cultures were cotransfected with green fluorescent protein (GFP; $0.04 \mu \mathrm{g} / \mathrm{well}$ ), and LIMK1 wild type ( $0.06 \mu \mathrm{g} /$ well) or LIMK1-kinase dead $(0.06 \mu \mathrm{g} / \mathrm{well})$, by using Lipofectamine $2000(0.4 \mu \mathrm{l} /$ well; Invitrogen $)$ in OptiMEM (8 $\mu \mathrm{l} /$ well; Invitrogen) transfection medium. After $3 \mathrm{~h}$, the medium was replaced with DMEM plus N2 and B27 supplement (Invitrogen) medium plus the respective treatments. At the indicated time, the cultures were fixed with $4 \%$ paraformaldehyde and $0.2 \mathrm{~m}$ sucrose and analyzed by fluorescence microscopy.

Morphometric analysis. Individual neurons were characterized as dystrophic according to defined morphological features (Grace et al., 2002; Grace and Busciglio, 2003). Briefly, dystrophic neurons were characterized by obvious aberrant morphology of neurites, such as acute angles, loops, or processes growing upward. Dendritic length was determined in MAP2-immunolabeled cultures; random images of individual neurons 

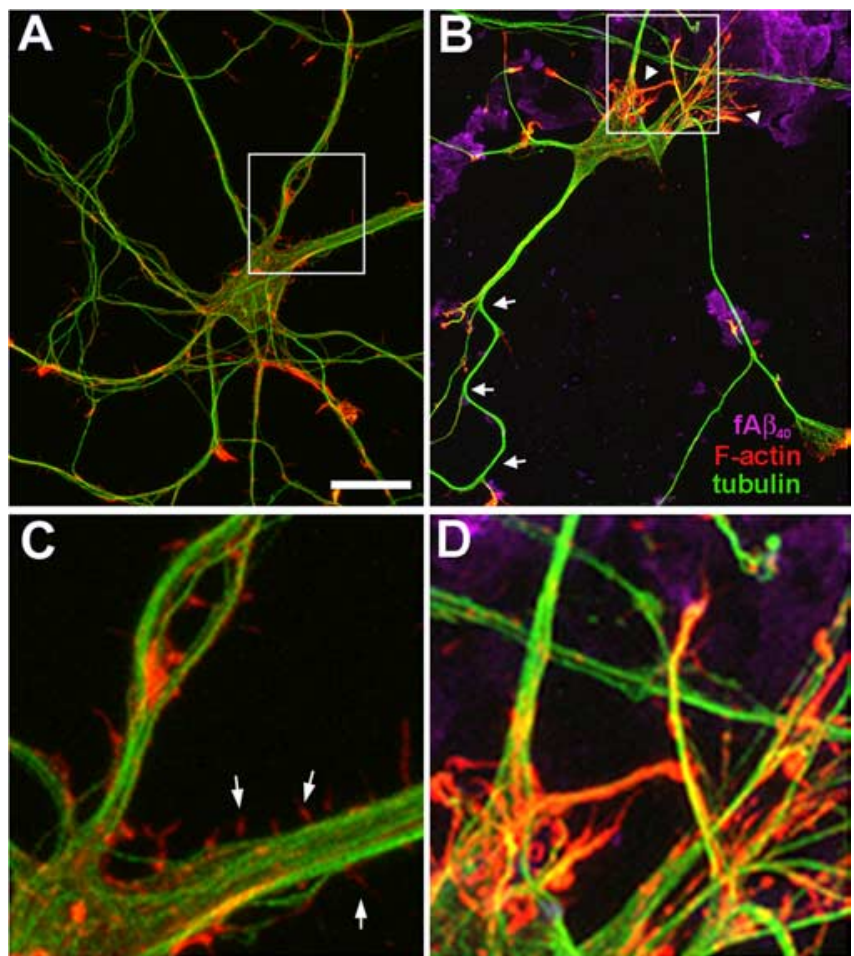

Figure 1. $\quad f A \beta$ induces neuronal dystrophy associated with altered organization of actin filaments. Rat hippocampal cultures were treated with vehicle or $20 \mu \mathrm{m} f A \beta 1-40$ (fA $\beta_{40}$ ) at day 7 , fixed $1 \mathrm{~d}$ later, and stained with rhodamine-phalloidin (red) and with antibodies to $A \beta$ (blue) and to tubulin class III (green). $\boldsymbol{A}, \boldsymbol{B}$, Confocal images taken at $40 \times$ magnification. $\boldsymbol{C}, \boldsymbol{D}$, Enlargements of the area depicted in $\boldsymbol{A}$ and $\boldsymbol{B}$, respectively. $\boldsymbol{A}, \boldsymbol{C}$, Control neurons exhibit smooth and healthy appearance of neurites with small bundles of actin filaments at the tips of neurites and in delicate filopodia extending from the neuritic shaft (C, arrows). $\boldsymbol{B}$, Neurons treated with $\mathrm{fA} \beta$ show aberrant neuritic morphology, including altered neuritic caliber, increased tortuosity (arrows), reduced extension of the neuritic network, and aberrant branching and sprouting of neurites. $\boldsymbol{D}$, Large bundles of actin filaments are observed in dystrophic neurites in proximities to $f A \beta$ deposits ( $B$, arrowhead). Scale bar, $20 \mu \mathrm{m}$.

were taken at $40 \times$ magnification, and 80 neurons were analyzed using MetaMorph software.

Assessment of neuronal viability. To score neuronal viability in nontransfected cultures, the number of healthy nuclei per unit area after Hoechst staining was assessed using a combination of fluorescent illumination and phase contrast, which allowed the identification of individual neurons that were unequivocally healthy on the basis of its nuclear appearance. In GFP/LIMK1-cotransfected cultures, neuronal viability was assessed by counting GFP-expressing neurons per unit area as described previously (Arrasate et al., 2004).

Statistics. All experiments were performed on triplicate samples and replicated at least three times. Statistical comparisons were performed using Student's $t$ test or ANOVA, followed by post hoc comparisons. Data are expressed as the percentage of the mean \pm SEM with respect to the vehicle-treated control.

\section{Results}

$A \beta$ fibrils induce neuronal dystrophy and increase phosphorylation of ADF/cofilin and LIMK1

Rat hippocampal neurons in cultures show an extensive neurite network, with a smooth and healthy appearance of neurites as evidenced by tubulin class III immunostaining (Fig. $1 A$ ). Treatment with $20 \mu \mathrm{M}$ fibrillar $\mathrm{A} \beta$ (fA $\beta$ ) for $24 \mathrm{~h}$ resulted in neuronal dystrophy. Dystrophic neurons exhibit several abnormal morphological features including deformation and contortion of neurites, aberrant outgrowth of neuritic processes from the cell body, and a dramatic reduction in the axonal network (Fig. $1 B$ )
(Busciglio et al., 1992; Grace et al., 2002; Heredia et al., 2004). Neuronal dystrophy is accompanied by a dramatic reorganization of actin filaments, as evidenced by rhodamine-phalloidin labeling. In control cultures, actin filaments are mainly observed at the tips of the neurites and in delicate filopodia extending at the sides of neuritic shafts (Fig. $1 A, C$ ). In contrast, in $\mathrm{fA} \beta$-treated cultures, dense phalloidin staining is found in dystrophic neurites in the proximity of $\mathrm{fA} \beta$ deposits (Fig. $1 C, D$ ), indicating that $\mathrm{fA} \beta$ deposition is linked to altered organization of actin filaments and neuritic dystrophy. Therefore, to address whether ADF/cofilin activity is altered by $A \beta$, we used an antibody that specifically recognizes inactive, Ser3-phosphorylated-ADF/cofilin (Pcofilin). Rat hippocampal cultures were treated with vehicle or with $\mathrm{fA} \beta$ and analyzed by immunofluorescence. Triplefluorescence confocal microscopy showed that $\mathrm{fA} \beta$ increases $\mathrm{P}$-cofilin fluorescence intensity in hippocampal cultures (Fig. $2 A$ ). This increase was associated with a dramatic remodeling of actin filaments and with neuritic dystrophy, as evidenced by rhodamine-phalloidin and tubulin class III labeling, respectively (Fig. 2A). To confirm that the increase in the P-cofilin level is attributable to the toxic fibrillar form of $A \beta$, cultures were treated with vehicle (control), soluble monomeric $\mathrm{A} \beta(\mathrm{s} A \beta)$ or $\mathrm{fA} \beta$ for $24 \mathrm{~h}$ and analyzed by Western blot. A significant increase in the $\mathrm{P}$-cofilin level was confirmed in $\mathrm{fA} \beta$-treated cultures (ANOVA; $F_{(2,5)}=10.44 ; p<0.016$, LSD post hoc test) (Fig. $2 B$ ); in contrast, the level of P-cofilin was not altered by $s \mathrm{~A} \beta$, indicating that $\mathrm{ADF} /$ cofilin phosphorylation depends on the state of aggregation of $\mathrm{A} \beta$. It was shown previously that $\mathrm{A} \beta$ may stimulate neurite outgrowth through the cell adhesion domain RHDS spanning residues 5-8 of the A $\beta$ sequence (Ghiso et al., 1992; Saporito-Irwin and Van Nostrand, 1995). To determine the role of the RHDS domain in $A \beta$-induced neuronal dystrophy, we analyzed the effect of $A \beta 25-35$ peptide, which lacks the RHDS domain but can form fibrils and induce neurotoxicity (Yankner et al., 1990; Hughes et al., 2000). A time-course analysis of P-cofilin showed that $\mathrm{A} \beta 25-35$ induces a persistent increase in Ser3 phosphorylation of ADF/cofilin over the period analyzed (ANOVA; $F_{(3,11)}=$ 7.29; $p<0.005$, LSD post hoc test) (Fig. 2C). These experiments indicate that $\mathrm{fA} \beta$-induced neuronal dystrophy is associated with a persistent inactivation of $\mathrm{ADF} / \mathrm{cofilin}$ and a rearrangement of actin filaments.

LIM kinases can induce inactivation of ADF/cofilin by phosphorylation at its Ser3 (Arber et al., 1998). LIMK1, a LIMK family member predominantly expressed in the nervous system, is activated by phosphorylation at Thr508 (Edwards et al., 1999). To explore whether LIMK1 activity is altered by $\mathrm{fA} \beta$, we used an antibody that selectively recognizes LIMK1 phosphorylated at Thr508. Treatment of hippocampal cultures with $\mathrm{fA} \beta$ resulted in an increased level of P-LIMK1 as evidenced by immunofluorescence (Fig. 3A). Densitometric determination using MetaMorph software showed a significant $30 \pm 10.2 \%$ increase in P-LIMK1 in the soma (ANOVA; $F_{(1,29)}=6.16 ; p \leq 0.019$ ) and a $35 \pm 6.2 \%$ increase in P-LIMK1 in proximal neurites (ANOVA; $F_{(1,29)}=$ $18.51 ; p<0.001)$ compared with vehicle-treated control cultures. Western blot showed that increased levels of P-LIMK1 were not associated with an overall increase in LIMK1 levels (Fig. 3B). Together, these experiments show that $\mathrm{A} \beta$ fibril deposition increases the activity of LIMK1 in hippocampal cultures.

\section{ADF/cofilin phosphorylation by LIMK1 mediates fA $\beta$-induced neuronal dystrophy}

To determine whether inactivation of $\mathrm{ADF} /$ cofilin by endogenous LIMK1 is required for $\mathrm{fA} \beta$-induced neuronal dystrophy, a 
A
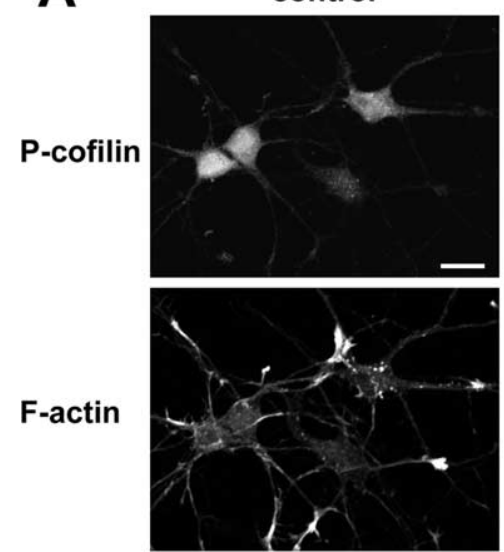

tubulin

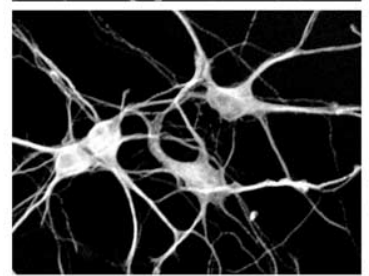

B
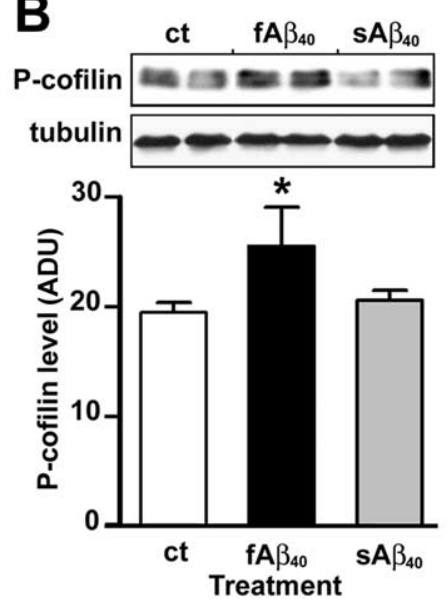
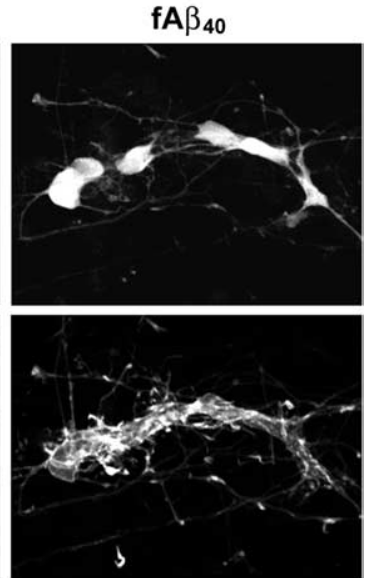

A

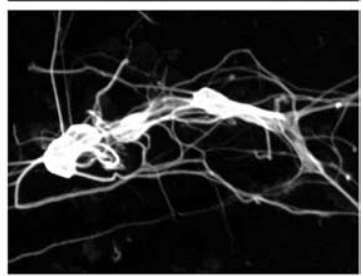

C Time after $\mathrm{fA} \beta_{35}(\mathrm{~h})$
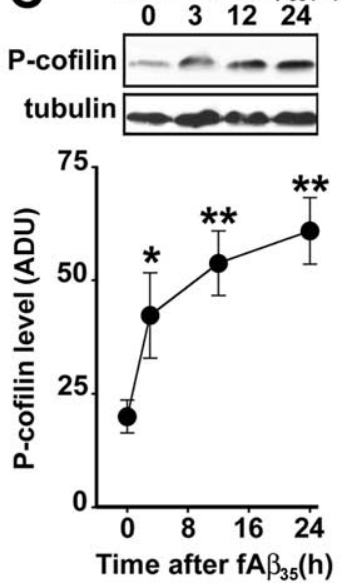

Figure 2. $f A \beta$ induces neuronal dystrophy and increased phosphorylation of cofilin. $A$, Rat hippocampal cultures were treated at day 7 with vehicle (control) or $20 \mu \mathrm{m}$ fibrillar $\mathrm{A} \beta 1-40$ $\left(\mathrm{fA} \beta_{40}\right)$ and fixed at day 8 . Confocal images were taken of cultures stained with rhodaminephalloidin (F-actin) and with antibodies to P-cofilin and to tubulin class III (tubulin). Note that $\mathrm{fA} \beta$-treated cultures exhibit an increased level in P-cofilin and altered distribution of $F$-actin and significant neuritic dystrophy. Scale bar, $20 \mu \mathrm{m}$. B. Hippocampal cultures were treated with vehicle (ct), $20 \mu \mathrm{m}$ fibrillar $A \beta 1-40$ (fA $\left.\beta_{40}\right)$, or $20 \mu \mathrm{m}$ soluble $A \beta 1-40\left(\mathrm{sA} \beta_{40}\right)$ and harvested after $24 \mathrm{~h}$. Cell lysates were analyzed in triplicate by Western blot with antibodies against $P$-cofilin and tubulin; densitometric determination showed a significant increase in the P-cofilin level after $\mathrm{fA} \beta$ treatment ( ${ }^{*} p<0.016$, ANOVA followed by the LSD post hoc test). Similar results were obtained in at least three independent experiments. $C$, Rat hippocampal cultures were treated with $20 \mu \mathrm{m} \mathrm{fA} \beta 25-35\left(\mathrm{fA} \beta_{35}\right)$ for the indicated period of time, and the levels of $P$-cofilin and tubulin were analyzed in triplicate samples by densitometry after Western blot with specific antibodies. A significant increase in the P-cofilin level was observed after $\mathrm{fA} \beta$ at all time points analyzed $\left({ }^{*} p<0.005,{ }^{* *} p<0.001\right.$, ANOVA followed by the LSD post hoc test). Plots are shown in arbitrary desitometric units (ADU). Error bars indicate SEM.

synthetic peptide, S3 peptide, which contains the unique Ser3 phosphorylation site of ADF/cofilin and a penetrating sequence to allow neuronal internalization of the peptide from the culture medium, was used as a specific competitor substrate for active LIMK1 (Fig. 4A). This peptide has been successfully used to prevent LIMK1-mediated phosphorylation of ADF/cofilin after
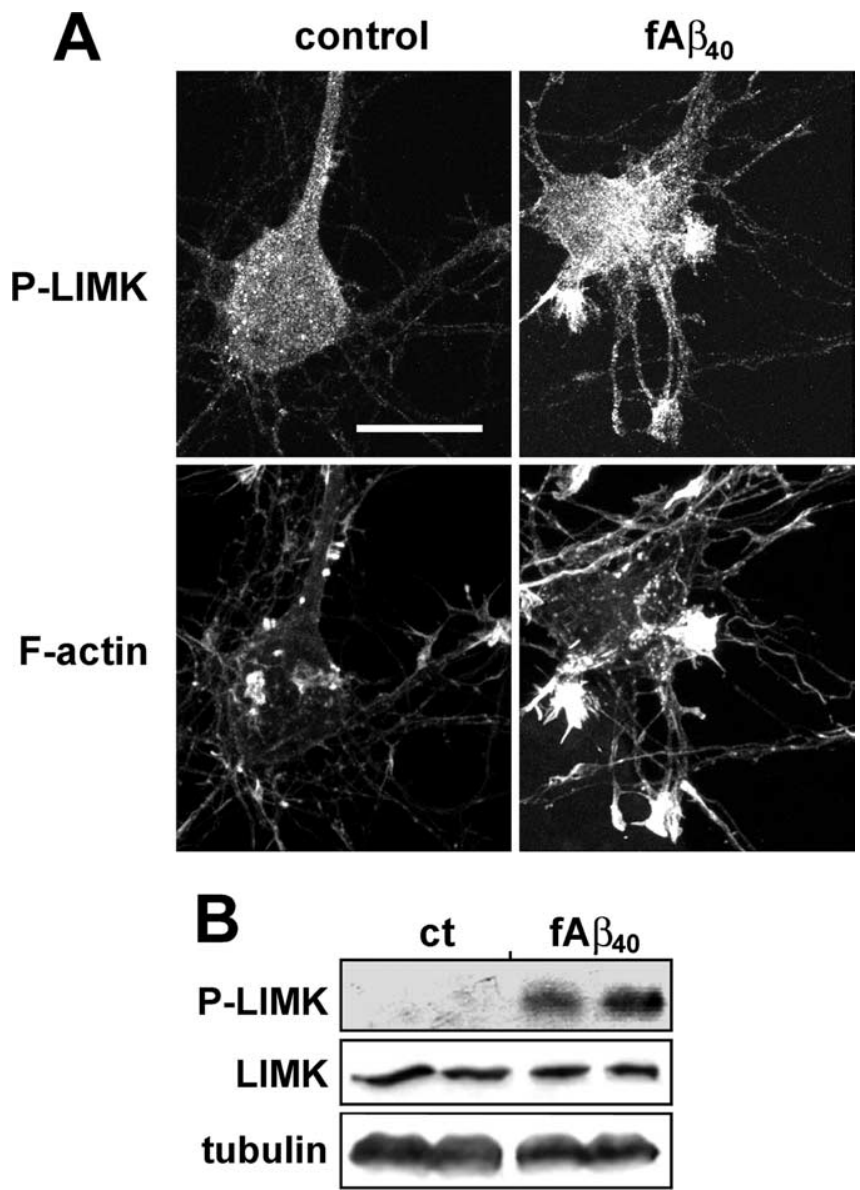

Figure 3. Activation of LIMK1 by $\mathrm{fA} \beta$. Rat hippocampal cultures were treated with vehicle (control) or $20 \mu \mathrm{m} f A \beta 1-40$ (fA $\beta_{40}$ ) from day 7 to day 8 and fixed for immunolabeling or harvested for Western blot analysis and labeled with antibody to LIMK1 and P-LIMK1. A, Hippocampal neurons were immunolabeled with anti-P-LIMK1 and stained with rhodamine-phaIloidin (F-actin), and immunofluorescent images were taken with identical settings; note the increase in P-LIMK1 after $\mathrm{AA} \beta 1-40$ treatment, which mostly overlap with increased F-actin. Scale bar, $20 \mu \mathrm{m}$. B. Western blot showing the levels of P-LIMK1, LIMK1, and tubulin in control (ct) and cultures treated with $\mathrm{fA} \beta 1-40$.

semaphorin 3A treatment (Aizawa et al., 2001). As expected, the addition of the S3 peptide to hippocampal cultures reduces the endogenous levels of P-cofilin in a time- and dose-dependent manner (Fig. 4B). More importantly, Western blot and densitometric determinations showed that $\mathrm{S} 3$ peptide significantly abolished the increase in P-cofilin induced by fA $\beta$ (Fig. 4C) (ANOVA; $\left.F_{(4,10)}=15.34 ; p<0.0003\right)$. Besides, immunofluorescence analysis also showed that S3 peptide dramatically reduced the increase in P-cofilin induced by fA $\beta$ after $6 \mathrm{~h}$ of treatment (Fig. $4 D$ ), interestingly, this was accompanied by a significant reduction in actin filament rearrangement (Fig. 4D). These experiments indicate that $\mathrm{S} 3$ peptide efficiently inhibits $\mathrm{A} \beta$-induced $\mathrm{ADF} /$ cofilin phosphorylation.

To determine the role of $\mathrm{ADF} /$ cofilin activity on $\mathrm{A} \beta$-induced neuronal dystrophy, cultures were treated for $24 \mathrm{~h}$ with vehicle or $20 \mu \mathrm{M} \mathrm{fA} \beta$, with or without S3 peptide $(7.5 \mu \mathrm{g} / \mathrm{ml})$; neuritic morphology was analyzed after tubulin class III immunolabeling. Treatment with $\mathrm{fA} \beta$ caused a striking loss of axonal and dendritic processes as evidenced by a dramatic reduction in the neuritic network in the culture (Fig. 5); this reduction was prevented by S3 peptide (Fig. 5). An accurate determination in the reduction in axonal and dendritic length induced by fA $\beta$ in these cultures was 


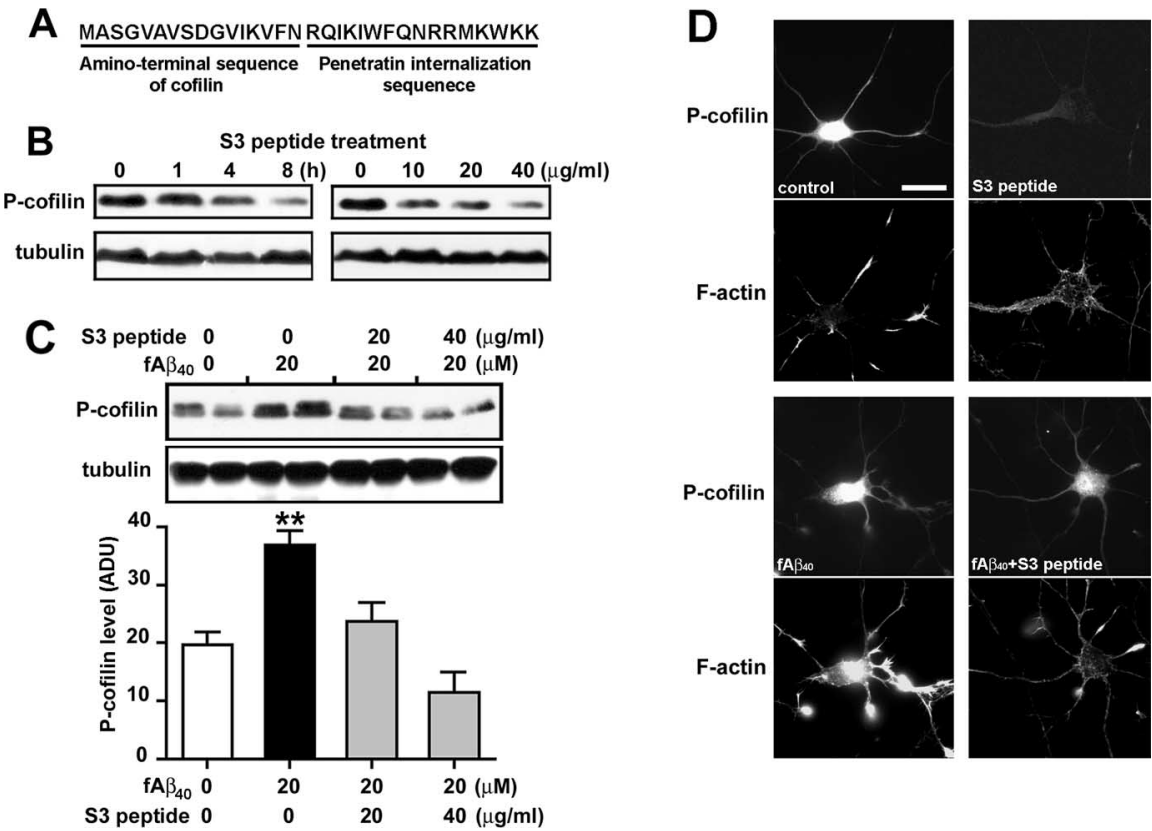

Figure 4. $S 3$ peptide inhibits $f A \beta$-induced phosphorylation of cofilin by LIMK1. $\boldsymbol{A}$, Structure of $S 3$ peptide. $\boldsymbol{B}$, Time- and concentration-dependent inhibition of endogenous cofilin phosphorylation by $\$ 3$ peptide. Rat hippocampal cultures were treated with vehicle or with $20 \mu \mathrm{g} / \mathrm{ml} \mathrm{S3}$ peptide for the indicated time period (left) or treated with the indicated concentration of S3 peptide for $4 \mathrm{~h}$ (right); the level of P-cofilin and tubulin were analyzed by Western blot. $\boldsymbol{C}$, Rat hippocampal cultures were treated with the indicated concentrations of $S 3$ peptide and $f A \beta 1-40\left(f A \beta_{40}\right)$ for $6 h$, and the level of $P$-cofilin was analyzed in triplicate samples by Western blot and densitometry. Plots are shown in arbitrary desitometric units (ADU). ${ }^{* *} p<0.0003, \mathrm{fA} \beta$ versus control and S3 peptide (by ANOVA). Note that treatment with S3 peptide inhibits the increase in P-cofilin induced by fA $\beta$. Error bars indicate SEM. D, Rat hippocampal cultures were treated for $6 \mathrm{~h}$ with vehicle (control), $20 \mu \mathrm{g} / \mathrm{ml} \mathrm{S3}$ peptide, or $20 \mu \mathrm{m}$ $\mathrm{fA} \beta 1-40$, fixed, and immunolabeled with anti-P-cofilin antibody and F-actin. Confocal microscopy images were taken with identical settings. Scale bar, $20 \mu \mathrm{m}$.

not possible because of the extensive development of neurites in control and S3 peptide-treated cultures. To overcome this difficulty, dendritic length was measured after MAP2 immunolabeling, as a quantitative estimate of neuritic dystrophy. Similar to tubulin-stained cultures, MAP2-labeled neurons showed a dramatic reduction in the length of MAP2-positive dendrites after $\mathrm{fA} \beta$ treatment; this effect was abolished by cotreatment with the $\mathrm{S} 3$ peptide (Fig. $6 A$ ). Thus, $\mathrm{fA} \beta$ induced a significant $52.3 \pm 6.1 \%$ reduction in dendritic length compared with vehicle-treated control cultures ( $p<0.0001$; ANOVA and LSD post hoc test); the addition of S3 peptide alone did not alter dendritic length, but it completely inhibited the detrimental effect of $\mathrm{fA} \beta$ on dendritic length (Fig. $6 A, B$ ). In addition, we observed that other morphological abnormalities induced by $\mathrm{fA} \beta$, such as tortuosity and aberrant branching and sprouting of neurites were also reduced by S3 peptide. Altogether, these experiments indicate that fA $\beta$ induced neuronal dystrophy requires LIMK1-mediated inactivation of $\mathrm{ADF} /$ cofilin.

\section{LIMK1 activity and $\mathrm{A} \boldsymbol{\beta}$-induced neuronal death}

To address the potential involvement of LIMK1 in more advanced stages of $A \beta$-induced neuronal degeneration, we analyzed the effect of S3 peptide in $\mathrm{A} \beta$-induced neuronal death. Rat hippocampal cultures were treated with vehicle (control) or $20 \mu \mathrm{M}$ $\mathrm{fA} \beta$ with or without the addition of S3 peptide, and $24 \mathrm{~h}$ later, neuronal viability was determined by Hoechst staining. In fA $\beta$ treated cultures, the number of viable neurons was reduced to $54 \pm 18 \%$ with respect to control cultures. In contrast, a significant reduction in $\mathrm{fA} \beta$ toxicity was observed in cultures treated with S3 peptide; the number of viable neurons in these cultures was $84 \pm 13 \%$ (Fig. 7A). Statistical analysis indicates that toxicity induced by $\mathrm{fA} \beta$ was significantly inhibited by S3 peptide, whereas S3 peptide alone did not alter neuronal viability in an appreciable manner $\left(\operatorname{ANOVA} ; F_{(3,36)}=23.32 ; p<0 ; 001\right.$, LSD post hoc test). These data suggest that LIMK1-mediated phosphorylation of $\mathrm{ADF} /$ cofilin is also involved in $\mathrm{A} \beta$-induced neuronal death. To further confirm the involvement of LIMK1 in A $\beta$-induced neuronal death by an independent method, rat hippocampal cultures were cotransfected with the GFP and with either full-length wild-type LIMK1 (wtLIMK1) or full-length LIMK1 carrying a point mutation at 360th Lys by Met that abolish its kinase activity (kd-LIMK1) (Sumi et al., 1999). Immunofluorescence analysis revealed a high degree $(>80 \%)$ of GFP-LIMK1 cotransfection. In addition, we observed that overexpression of wtLIMK1 was accompanied by increased staining for F-actin, whereas overexpression of kd-LIMK1 resulted in faint staining with rhodamine-phalloidin, consistent with a previous study (Rosso et al., 2004). We found that treatment with $\mathrm{fA} \beta$ resulted in a $55 \pm 6 \%$ reduction in neuronal viability in GFP/wt-LIMK1-cotransfected cultures. Neuronal viability was only slightly decreased to $95 \pm 6 \%$ in cultures treated with $\mathrm{fA} \beta$ and S3 peptide (Fig. $7 B)$. Statistical comparison indicates that $S 3$ peptide significantly inhibited fA $\beta$-induced neuronal loss $\left(\mathrm{ANOVA} ; F_{(3,12)}=4.1464\right.$; $p<0.01$, LSD post hoc test). In contrast, $\mathrm{fA} \beta$ induced a nonsignificant $92 \pm 9 \%$ change in viability in cultures cotransfected with GFP and kd-LIMK1 (ANOVA; $F_{(3,12)}=0.69154 ; p=\mathrm{NS}$ ) (Fig. 7C). Altogether, these experiments indicate that LIMK1 activity is implicated in the mechanisms of $\mathrm{A} \beta$-induced dystrophy and neuronal death.

\section{LIMK1 activity in AD brain}

We then analyzed the presence of active LIMK1 in brain sections of entorhinal cortex and hippocampal formation in human brain. In normal human brain, sporadic neurons stained positive for P-LIMK1. Immunofluorescence of P-LIMK1 was observed in neuronal cell bodies and processes but was essentially excluded from glial cells (data not shown). Three-dimensional reconstruction images revealed that P-LIMK1 localized as patches at the cell surface of the neuron, suggesting that LIMK1 activation might occur mainly in association with the cell membrane. In sporadic human $\mathrm{AD}$ brain, only occasional neurons stained positive for P-LIMK1 in areas free of AD pathology (frequency, $0.68 \pm 0.17$ neurons/field; see Materials and Methods) (Fig. $8 \mathrm{~A}$ ); in contrast, a dramatic increase in the number of P-LIMK1-positive neurons was clearly observed in $\mathrm{AD}$ pathology-rich areas of the same cortex (Fig. 8B,C). Quantitative analysis confirmed a highly significant increase in the number of neurons that were positive for P-LIMK1 in $\mathrm{A} \beta$ pathology-rich areas (frequency, $12.75+2.13$ neurons/field) compared with $\mathrm{A} \beta$ pathology-free areas $(t=$ 11.609; $\mathrm{df}=18 ; p<0.0001$, Student's $t$ test) (Fig. $8 D$ ). Similarly, the number of P-LIMK1-positive neurons significantly increased 

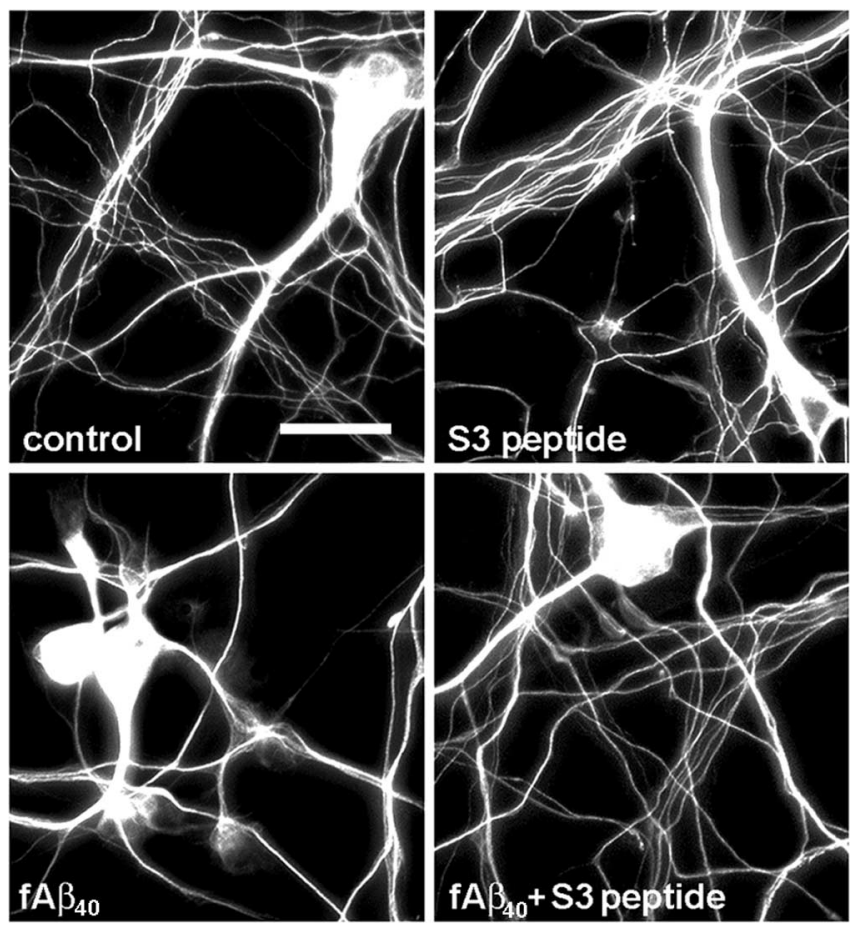

Figure 5. $S 3$ peptide prevents $f A \beta$-induced neuritic loss. Rat hippocampal cultures were treated for $24 \mathrm{~h}$ with vehicle (control) and $20 \mu \mathrm{mfA} \beta 1-40\left(\mathrm{fA} \beta_{40}\right.$ ) with or without $7.5 \mu \mathrm{g} / \mathrm{ml}$ S3 peptide. The cultures were fixed and immunolabeled with anti-tubulin class III antibody and analyzed by immunofluorescence microscopy. Fluorescent images were taken at $40 \times$ magnification with identical settings. Note that $\$ 3$ peptide dramatically reduces the loss of neurites induced by fA $\beta$. Scale bar, $20 \mu \mathrm{m}$.

in areas affect by tau pathology $(7.87+0.54$ neurons/field $)$ compared with tau pathology-free areas $(t=15.790 ; \mathrm{df}=22 ; p<$ 0.0001 , Student's $t$ test) (Fig. $8 D$ ). In addition, P-LIMK1 immunofluorescence was found in neurons showing intracellular accumulation of $\mathrm{A} \beta$ and diffuse, pretangle phosphorylated tau (Fig. $8 E, F)$, which are indicators of an early stage of neuronal degeneration (Gouras et al., 2000; Busciglio et al., 2002; Oddo et al., 2003). No P-LIMK1 labeling was associated with late markers of degeneration such as extracellular ghost tangles or $\mathrm{A} \beta$-plaque cores (P. Helguera and J. Busciglio, unpublished observation). Thus, LIMK1 activity is increased in AD brain, in neurons displaying markers of $\mathrm{AD}$ pathology.

\section{Discussion}

Dystrophic neurites are a direct cause of cognitive impairment in AD (McKee et al., 1991; Benzing et al., 1993; Knowles et al., 1999; Brendza et al., 2003; Stern et al., 2004; Tsai et al., 2004), therefore deciphering the molecular mechanism of dystrophy might pave the way for novel therapeutic modalities for $\mathrm{AD}$. The recent findings showing that local applications of antibodies to $\mathrm{A} \beta$ can rapidly revert neuritic dystrophy in vivo (Lombardo et al., 2003; Brendza et al., 2005) further support this possibility. Here, we demonstrate that $\mathrm{A} \beta$ dystrophy requires LIMK1-mediated phosphorylation of $\mathrm{ADF} / \mathrm{cofilin}$ and the remodeling of the actin cytoskeleton. Previous reports showed that $\mathrm{A} \beta$ deposition was linked to increased accumulation of actin filaments and treatment with actin depolymerizing agents, such as cytochalasin $D$ or lantrunculin $\mathrm{B}$, inhibited $\mathrm{A} \beta$ degeneration (Furukawa and Mattson, 1995; Himura et al., 2003); our in vitro data are in agreement with these observations and provide a molecular mechanism for $\mathrm{A} \beta$-induced actin remodeling. We found that treatment of neu-
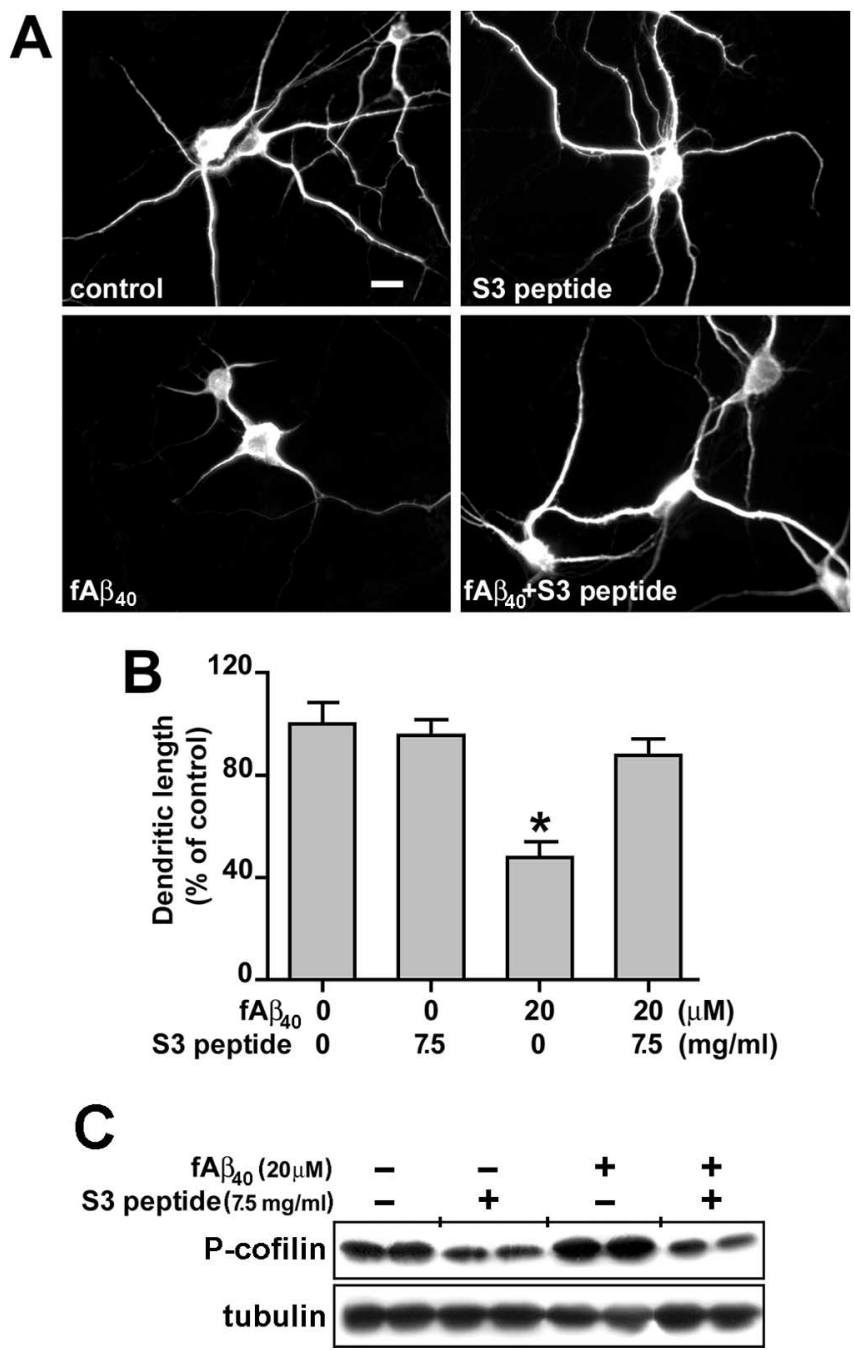

Figure 6. $S 3$ peptide counteracts $f A \beta$-induced dendritic retraction. Rat hippocampal cultures were treated for $24 \mathrm{~h}$ with vehicle (control) or $20 \mu \mathrm{m} \mathrm{fA} \beta 1-40$ ( $\mathrm{fA} \beta_{40}$ ), with or without $7.5 \mu \mathrm{g} / \mathrm{ml} \mathrm{S3}$ peptide, and fixed and immunolabeled with anti-MAP2 antibody. $A$, Fluorescent images were taken at $40 \times$ magnification. Note that $\$ 3$ peptide prevents the reduction in dendritic length induced by $\mathrm{fA} \beta$. Scale bar, $20 \mu \mathrm{m}$. $\boldsymbol{B}$, The length of MAP2-positive dendrites was determined in 80 neurons from triplicate samples using MetaMorph software; statistical comparisons were made by ANOVA and the LSD post hoc test. ${ }^{*} p<0.0001$, fA $\beta$ versus control and S3 peptide-treated cultures. Error bars indicate SEM. C, Western blot analysis showing the levels of $\mathrm{P}$-cofilin and tubulin after $24 \mathrm{~h}$ of treatment with the indicated concentrations of $\mathrm{fA} \beta 1-40$ and $\mathrm{S} 3$ peptide; samples are shown by duplicate.

ronal cultures with $A \beta$ fibrils significantly increased the accumulation of actin filaments and the levels of the active P-LIMK1 and inactive Ser3-phosphorylated ADF/cofilin. Because ADF/cofilin is the only known substrate for LIMK1 in nerve cells (Bamburg and Wiggan, 2002; Meyer and Feldman, 2002), its inactivation by LIMK1, might result in actin filament accumulation. This interpretation is consistent with previously reported effects of LIMK1 (Endo et al., 2003; Rosso et al., 2004). Importantly, the nontoxic soluble-monomeric form of A $\beta 1-40$ did not induce dystrophy (Busciglio et al., 1992; Heredia et al., 2004), nor did it promote actin filament accumulation or increase the P-cofilin level, indicating that the conversion of $\mathrm{A} \beta$ to the fibrillar form is required to activate LIMK1 and to promote actin remodeling and dystrophy. Additionally, we found that other toxic insults that do not induce neuritic dystrophy, such as hydrogen peroxide, serum withdrawal, and NMDA, did not increase the P-LIMK1 level (L. Here- 
A

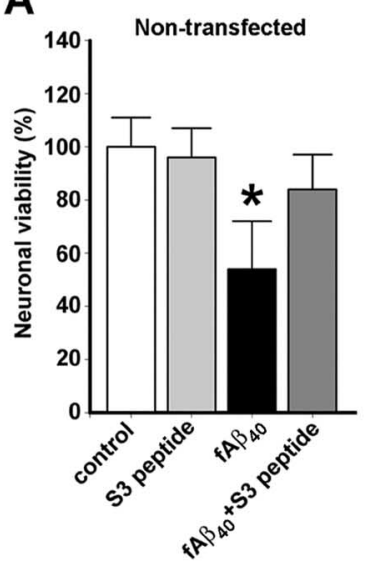

B

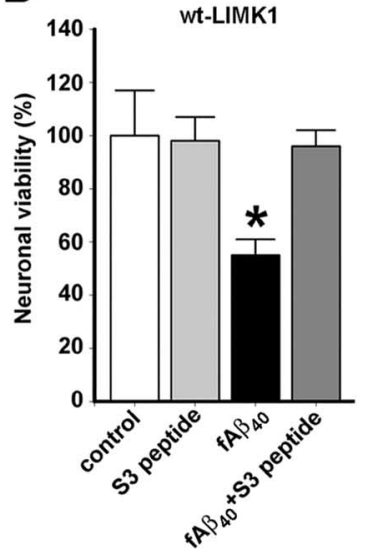

C

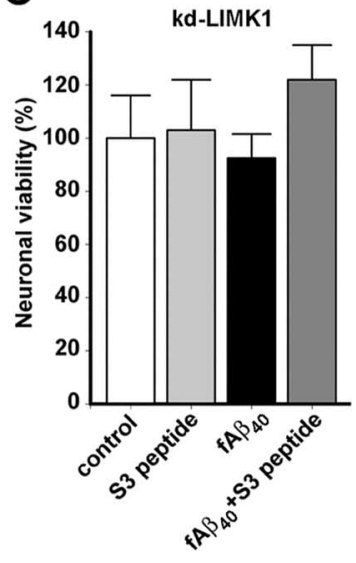

Figure 7. LIMK1 and $\mathrm{AA} \beta$-induced neuronal death. Rat hippocampal cultures were treated with vehicle (control) or $20 \mu \mathrm{M}$ $\mathrm{fA} \beta 1-40$ (fA $\beta_{40}$ ), with or without $7.5 \mu \mathrm{g} / \mathrm{ml} \mathrm{S3}$ peptide, and the number of viable neurons was scored. $A$, In nontransfected cultures, the effect of $f A \beta 1-40$ and $S 3$ peptide on neuronal viability was assessed $24 \mathrm{~h}$ after treatment by Hoechst staining. $B, C$, In cultures that were cotransfected with GFP and either wt-LIMK1 $(\boldsymbol{B})$ or kd-LIMK1 $(\boldsymbol{C})$, neuronal viability was assessed $18 \mathrm{~h}$ after treatment by scoring GFP-expressing neurons. $A$, Representative experiment showing the effect of $\mathrm{fA} \beta$ and $S 3$ peptide in neuronal viability. More than 900 neurons were scored, and similar results were found in three independent experiments. Statistical comparisons were made by ANOVA $\left(F_{(3,36)}=23.32\right)$ and the LSD post hoc test. ${ }^{*} p<0.001, \mathrm{fA} \beta$ versus control, $\mathrm{S3}$ peptide, and $\mathrm{fA} \beta+$ S3peptide. $\boldsymbol{B}$, Effect of $\mathrm{fA} \beta$ and $\mathrm{S} 3$ peptide on neuronal viability in GFP/wt-LIMK1-cotransfected neurons. A representative experiment is shown, $>170$ neurons were scored, and similar results were found in three independent experiments. Statistical comparisons were made by ANOVA $\left(F_{(3,12)}=4.1464\right)$ and the LSD post hoc test. ${ }^{*} p<0.01, \mathrm{fA} \beta$ versus control, S3 peptide, and $\mathrm{fA} \beta+\mathrm{S} 3$ peptide. Note that toxicity of $\mathrm{f} A \beta$ is blocked by $\mathrm{S} 3$ peptide in nontransfected neuronal cultures that express endogenous levels of LIMK1 and in cultures that were transfected with wt-LIMK1. C, Effect of fA $\beta$ and S3 peptide on neuronal viability in GFP/kd-LIMK1-cotransfected culture. A representative experiment is shown, $>110$ neurons were scored, and similar results were found in three independent experiments. No significant effect of $f A \beta$ in neuronal viability was observed; statistical comparisons were made by ANOVA $\left(F_{(3,12)}=0.69154 ; p=N S\right)$. Note that kd-LIMK transfection inhibits $\mathrm{fA} \beta$-induced neuronal death. Error bars indicate SEM.

dia and A. Lorenzo, unpublished observations), indicating that toxicity per se does not induce LIMK1 phosphorylation. Collectively, these observations suggest that neuritic dystrophy and LIMK1 activation are specific responses to the deposition of toxic levels of $\mathrm{A} \beta$ fibrils. Furthermore, we showed that S3 peptide, a specific LIMK competitor for ADF/cofilin phosphorylation (Aizawa et al., 2001), inhibited $A \beta$ fibril-induced ADF/cofilin phosphorylation, actin filament accumulation, neuritic dystrophy, and cell death. In addition, overexpression of the kinase dead form of LIMK1 also inhibited fA $\beta$-induced neuronal cell death, thus demonstrating that the activity of LIMK1 is required for $\mathrm{A} \beta$ fibril-induced actin filament remodeling and neuronal degeneration. Alterations in the actin cytoskeleton different from the one described here have been observed recently in neuronal cultures after $\mathrm{A} \beta$ treatment (Maloney et al., 2005). These authors showed that low doses of $\mathrm{A} \beta$ can promote $\mathrm{ADF} /$ cofilin activation and actin-rod formation in cultured neurons. Actin rods are inclusions of filamentous actin saturated with active ADF/cofilin (Minamide et al.,2000). Because ADF/cofilin activity depends on the state of Ser3 phosphorylation, which is regulated by the net balance of the kinase LIMK and the phosphatase Slingshot (Bamburg and Wiggan, 2002), it is possible that low subtoxic doses of $\mathrm{A} \beta$, such as those used by Maloney et al. (2005), may favor the net activity of Slingshot, whereas the net activity of LIMK1 could be favored by higher toxic doses of $A \beta$, such as those used in our study. Alternatively, it is possible that slightly different culture conditions may favor the formation of actin rods in a specific neuronal subpopulation and LIMK1 activation in others. Although more research is required to address these possibilities, our study and the work from Maloney et al. (2005) highlight the role of altered ADF/cofilin activity as an important factor contributing to actin pathology and neuronal degeneration in $\mathrm{AD}$.

In sporadic $\mathrm{AD}$ brain, the number of P-LIMK1-positive neurons was significantly increased in entorhinal cortex and hippocampal formation in association with $\mathrm{AD}$ pathology. LIMK1 activation did not appear to be a secondary event to intraneuronal accumulation of $\mathrm{A} \beta$ or hyperphosphorylated tau because some P-LIMK1-positive neurons in $\mathrm{A} \beta$ pathology-rich areas were devoid of these pathological markers. In addition, PLIMK1 labeling was not found in association with markers of late $\mathrm{AD}$ pathology, such as extracellular ghost tangles or the core of $A \beta$ plaques (P. Helguera and J. Busciglio, unpublished observations), indicating that LIMK1 activation may require the integrity of the neuronal membrane. Interestingly, in human brain, P-LIMK1 labeling was restricted mostly to patches; additional studies are in progress to address whether this labeling might correspond to focal adhesion-related structures or to other neuronal structures such as presynaptic or postsynaptic terminals, where LIMK1 may play a critical regulatory role (Turner, 2000; Meng et al., 2002; Hoogenraad et al., 2004; Chen et al., 2005).

A $\beta$ fibril-mediated LIMK1 activation might require the participation of cell-surface proteins. We demonstrated that $\mathrm{A} \beta$ fibrils are needed for LIMK1 activation in vitro; coincidently, conversion of $\mathrm{sA} \beta$ to the fibrillar form increases its binding to membrane proteins (Lorenzo et al., 2000). Several membrane proteins have been shown to participate in $A \beta$ induced apoptosis (Yuan and Yankner, 2000); in contrast, $A \beta P P$ and/or integrins could be the main cell-surface candidates for $\mathrm{A} \beta$ fibril-induced neuronal dystrophy. Both $\mathrm{A} \beta \mathrm{PP}$ and integrins participate in mechanisms of neuronal plasticity (Breen et al., 1991; Perez et al., 1997; Benson et al., 2000; Sabo et al. 2001a), bind to A $\beta$ fibrils (Sabo et al., 1995; Lorenzo et al., 2000; Van Nostrand et al., 2002), colocalize in adhesion sites (Storey et al., 1996; Yamazaki et al., 1997), and cluster around $\mathrm{A} \beta$ deposits in aberrant focal adhesion structures (Grace and Busciglio, 2003; Heredia et al., 2004). In fact, $A \beta$ dystrophy requires aberrant activation of focal adhesion proteins, including Paxillin (Grace and Busciglio, 2003), activation of which could also depend on A $\beta$ PP or integrins, through their interaction with different cytoplasmic proteins (Sabo et al., 2001b; Zambrano et al., 2001; Martin et al., 2002). Interestingly, LIMK1 and its activator PAK have been shown to colocalize with Paxillin in focal adhesions (Foletta et al., 2004; Chen et al., 2005). Thus, LIMK1 may be a key downstream effector for $\mathrm{A} \beta$ fibril-induced actin remodeling in the aberrant focal adhesion complex, providing the initial forces to remodel neuronal shape around $\mathrm{A} \beta$ deposits.

The identity of the upstream pathway involved in $\mathrm{fA} \beta$ mediated LIMK1 activation has not been defined. Although noncanonical or aberrant signaling pathways could not be excluded, it is likely that $\mathrm{fA} \beta$-mediated LIMK1 phosphorylation may require activation of the Rho family of small GTPases, including 
pathways of Rho/ROCK or Rac-cdc42/ PAK. It was found recently that defects in the PAK pathway may lead to actin pathology and cognitive deficits in $\mathrm{AD}$ (Zhao et al., 2006). These authors reported a general reduction in the levels and activity of PAK in AD brain. Interestingly, they also showed that the overall PAK defect is accompanied by abnormal, very intense intraneuronal staining of active PAK in a punctate pattern, and similar abnormalities were also found in neurons surrounding $\mathrm{A} \beta$ plaques in 22-month-old APPswe Tg2576 mice and in hippocampal neurons after $\mathrm{A} \beta$ treatment (Zhao et al., 2006). These observations suggest that focalized abnormal PAK activation may occur during the progression of $\mathrm{AD}$ pathology. Coincidently, we found that active LIMK1 in $\mathrm{AD}$ brain is restricted to intraneuronal patches reminiscent of those described for active PAK in AD brain. In addition, we observed increased P-LIMK1 labeling surrounding $\mathrm{A} \beta$ plaques in 30-month-old APP23 mice (Heredia, S. de Olmos, and Lorenzo, unpublished observations). Therefore, it is possible that during the progression of AD pathology, abnormal focalized activation of PAK and LIMK1 might coexist in specific neuronal populations as a consequence of $\mathrm{A} \beta$ deposition. Thus, our data together with those of Zhao et al. (2006) argue for the involvement of abnormal regulation of the pathway of the Rho family of small GTPases in AD neurodegeneration.

The ability of $A \beta$ fibrils to induce the phosphorylation of LIMK1 and to remodel neuritic morphology suggests the activation of a mechanism of neuronal plasticity reminiscent of that triggered by Semaphorin 3A or BMP7, which are soluble, extracellular physiological morphogens that require LIMK1 as a downstream effector for shaping neurites in early stages of neuronal development (Aizawa et al., 2001; Lee-Hoeflich et al., 2004). Physiological morphogens such as Semaphorin 3A or BMP7 are temporally and spatially regulated to model a functional neuronal architecture. In contrast, in $\mathrm{AD}$ brain, deposition of $\mathrm{A} \beta$ fibrils progresses uncontrolled during adulthood promoting a pathological rearrangement of the extracellular matrix (Thal et al., 2002), suggesting that a continuous alteration in the composition of the extracellular matrix may trigger a pathological mechanism of plasticity. In fact, a pathological mechanism of neuroplasticity has been proposed as a pivotal prime mover in AD (Cotman et al., 1998; Mesulam, 1999; Phinney et al., 1999). In this regard, the results of this work suggest that LIMK1 is a key effector in the mechanism of maladaptive neuroplasticity in AD. Consequently, strategies directed to suppress abnormal activation of LIMK1 might have therapeutic value to counteract neuronal degeneration and cognitive impairment in AD.

\section{References}

Aizawa H, Wakatsukim S, Ishii A, Moriyama K, Sasaki Y, Ohashi K, SekineAizawa Y, Sehara-Fujisawa A, Mizuno K, Goshima Y, Yahara I (2001) Phosphorylation of cofilin by LIMkinase is necessary for semaphorin 3Ainduced growth cone collapse. Nat Neurosci 4:367-373.
Arber S, Barbayannis F, Hanser H, Schneider C, Stanyon C, Bernard O, Caroni P (1998) Regulation of actin dynamics through phosphorylation of cofilin by LIM-kinase. Nature 393:805-812.

Arrasate M, Mitra S, Schweitzer E, Segal M, Finkbeiner S (2004) Inclusion body formation reduces levels of mutant huntingtin and the risk of neuronal death. Nature 431:810.

Bamburg JR, Wiggan OP (2002) ADF/cofilin and actin dynamics in disease. Trends Cell Biol 12:598-605.

Benson DL, Schnapp LM, Shapiro L, Huntley GW (2000) Making memories stick: cell-adhesion molecules in synaptic plasticity. Trends Cell Biol 10:473-482.

Benzing WC, Mufson EJ, Armstrong DM (1993) Alzheimer's disease-like dystrophic neurites characteristically associates with senile plaques are not found within other neurodegenerative diseases unless amyloid betaprotein deposition is present. Brain Res 606:10-18.

Breen KC, Bruce M, Anderton BH (1991) Beta amyloid precursor protein mediates neuronal cell-cell and cell-surface adhesion. J Neurosci Res 28:90-100.

Brendza RP, O’Brien C, Simmons K, McKeel DW, Kelly RB, Paul SM, Olney JW, Sanes JR, Holtzman DM (2003) PDAPP; YFP double transgenic mice: a tool to study amyloid-beta associated changes in axonal, dendritic, and synaptic structures. J Comp Neurol 456:375-383.

Brendza RP, Bacskai BJ, Cirrito JR, Simmons KA, Skoch JM, Klunk WE, Mathis CA, Bales KR, Paul SM, Hyman BT, Holtzman DM (2005) Antiamyloid $\beta$ antibody treatment promotes the rapid recovery of amyloidassociated neuritic dystrophy in PDAPP transgenic mice. J Clin Invest 115:428-433.

Busciglio J, Lorenzo A, Yankner BA (1992) Methodological variables in the assessment of beta amyloid neurotoxicity. Neurobiol. Aging 13:609-612.

Busciglio J, Lorenzo A, Yeh J, Yankner BA (1995) Beta-amyloid fibrils induce tau phosphorylation and loss of microtubule binding. Neuron 14:879-888.

Busciglio J, Pelsman A, Wong C, Pigino G, Yuan M, Mori H, Yankner BA 
(2002) Altered metabolism of the amyloid $\beta$ precursor protein is associated with mitochondria dysfunction in Down's syndrome. Neuron 33:677-688.

Chen G-C, Turano B, Ruest PJ, Hagel M, Settleman J, Thomas SM (2005) Regulation of Rho and Rac signaling to the actin cytoskeleton by Paxillin during Drosophila development. Mol Cell Biol 25:970-987.

Cotman CW, Hailer NP, Pfister KK, Soltesz I, Schachner M (1998) Cell adhesion molecules in neural plasticity and pathology: similar mechanisms, distinct organizations? Prog Neurobiol 55:659-669.

Edwards DC, Sanders LC, Bokoch GM, Gill GN (1999) Activation of LIMkinase by Pak1 couples Rac/Cdc42 GTPase signaling to actin cytoskeletal dynamics. Nat. Cell Biol 1:253-259.

Endo M, Ohashi K, Sasaki Y, Goshima Y, Niwa R, Uemura T, Mizuno K (2003) Control of growth cone motility and morphology by LIM kinase and slingshot via phosphorylation and dephosphorylation of cofilin. J Neurosci 23:2527-2537.

Foletta VC, Moussi N, Sarmiere PD, Bamburg JR, Bernard O (2004) LIM kinase 1 , a key regulator of actin dynamics, is widely expressed in embryonic and adult tissues. Exp Cell Res 294:392-405.

Furukawa K, Mattson MP (1995) Cytochalasins protect hippocampal neurons against amyloid beta-peptide toxicity: evidence that actin depolymerization suppresses $\mathrm{Ca}^{2+}$ influx. J Neurochem 65:1061-1068.

Ghiso J, Rostagno A, Gardella JE, Liem L, Gorevic PD, Frangione B (1992) A 109-amino-acid C-terminal fragment of Alzheimer's disease amyloid precursor protein contains a sequence, -RHDS-, that promotes cell adhesion. Biochem J 288:1053-1059.

Götz J, Chen F, van Dorpe J, Nitsch RM (2001) Formation of neurofibrillary tangles in P301l tau transgenic mice induced by Abeta 42 fibrils. Science 293:1446-1447.

Gouras GK, Tsai J, Naslund J, Vincent B, Edgar M, Checler F, Greenfield JP, Haroutunian V, Buxbaum JD, Xu H, Greengard P, Relkin NR (2000) Intraneuronal $\mathrm{A} \beta 42$ accumulation in human brain. Am J Pathol 156:15-20.

Grace E, Busciglio JA (2003) Aberrant activation of focal adhesion proteins mediates fibrillar amyloid $\beta$-induced neuronal dystrophy. J Neurosci 23:493-502.

Grace EA, Rabiner AC, Busciglio JA (2002) Characterization of neuronal dystrophy induced by fibrillar amyloid $\beta$ : implications for Alzheimer's disease. Neuroscience 114:265-273.

Hardy J, Selkoe DJ (2002) The amyloid hypothesis of Alzheimer's disease: progress and problems on the road to therapeutics. Science 297:353356.

Head E, Lott IT, Cribbs DH, Cotman CW, Rohn TT (2002) Beta-amyloid deposition and neurofibrillary tangle association with caspase activation in Down syndrome. Neurosci Lett 330:99-103.

Helguera P, Pelsman A, Pigino G, Wolvetang E, Head E, Busciglio J (2005) ets- 2 promotes the activation of a mitochondrial death pathway in Down's syndrome neurons. J Neurosci 25:2295-2303.

Heredia L, Lin R, Solá Vigo R, Kedikian R, Busciglio J, Lorenzo A (2004) Amyloid beta-induced neurodegeneration promotes cell surface accumulation of amyloid-beta precursor protein. Neurobiol Dis 16:617-629.

Himura H, Katakura S, Ichikawa T, Kawakami T (2003) Glutamate and amyloid $\beta$-protein rapidly inhibit fast axonal transport in cultured rat hippocampal neurons by different mechanisms. J Neurosci 23:8967-8977.

Hoogenraad CC, Akhmanova A, Galjart N, De Zeeuw CI (2004) LIMK1 and CLIP-115: linking cytoskeletal defects to Williams syndrome. BioEssay 26:141-150.

Hughes E, Burke RM, Doig AJ (2000) Inhibition of toxicity in the betaamyloid peptide fragment beta-(25-35) using $N$-methylated derivatives: a general strategy to prevent amyloid formation. J Biol Chem 275:25109-25115.

Knowles RB, Wyart C, Buldirev SV, Cruz L, Urbanc B, Hasselmo ME, Stanley HE, Hyman BT (1999) Plaque-induced neurite abnormalities: implications for disruption of neural networks in Alzheimer's disease. Proc Natl Acad Sci USA 96:5274-5279.

Lambert MP, Barlow AK, Chromy BA, Edwards C, Freed R, Liosatos M, Morgan TE, Rozovsky I, Trommer B, Viola KL, Wals P, Zhang C, Finch CE, Krafft GA, Klein WL (1998) Diffusible, nonfibrillar ligands derived from Abeta1-42 are potent central nervous system neurotoxins. Proc Natl Acad Sci USA 95:6448-6453.

Lee MS, Kwon YT, Li M, Peng J, Friedlander RM, Tsai LH (2000) Neurotoxicity induces cleavage of p35 to p25 by calpain. Nature 405:360-364.
Lee-Hoeflich ST, Causing CG, Podkowa M, Zhao X, Wrana JL, Attisano L (2004) Activation of LIMK1 by binding to the BMP receptor, BMPRII, regulates BMP-dependent dendritogenesis. EMBO J 23:4792-4801.

Lombardo JA, Stern EA, McLellan ME, Kajdasz ST, Hickey GA, Bacskai BJ, Hyman BT (2003) Amyloid- $\beta$ antibody treatment leads to rapid normalization of plaque-induced neuritic alterations. J Neurosci 23:10879-10883.

Lorenzo A, Yankner BA (1994) Beta-amyloid neurotoxicity requires fibril formation and is inhibited by congo red. Proc Natl Acad Sci USA 91:12243-12247.

Lorenzo A, Yuan M, Zhang Z, Paganetti P, Sturchler-Pierrat C, Staufenbiel M, Mautino J, Sol Vigo F, Sommer B, Yankner BA (2000) Amyloid beta interacts with amyloid precursor protein: a potential toxic mechanism in Alzheimer's disease. Nat Neurosci 3:460-464.

Maloney MT, Minamide LS, Kinley AW, Boyle JA, Bamburg JR (2005) $\beta$-Secretase-cleaved amyloid precursor protein accumulates at actin inclusions induced in neurons by stress or amyloid $\beta$ : a feedforward mechanism for Alzheimer's disease. J Neurosci 25:11313-11321.

Martin KH, Slack JK, Boerner SA, Martin CC, Parsons JT (2002) Integrin connections map: to infinity and beyond. Science 296:1652-1653.

McKee AC, Kosik KS, Kowal NW (1991) Neuritic pathology and dementia in Alzheimer's disease. Ann Neurol 30:156-165.

Meng Y, Zhang Y, Tregoubov V, Janus C, Cruz L, Jackson M, Lu W-Y, MacDonald JF, Wang JY, Falls DL, Jia Z (2002) Abnormal spine morphology and enhanced LTP in LIMK-1 knockout mice. Neuron 35:121-133.

Mesulam MM (1999) Neuroplasticity failure in Alzheimer's disease: bridging the gap between plaques and tangles. Neuron 24:521-529.

Meyer G, Feldman EL (2002) Signaling mechanisms that regulate actinbased motility processes in the nervous system. J Neurochem 83:490-503.

Minamide LS, Striegl AM, Boyle JA, Meberg PJ, Bamburg JR (2000) Neurodegenerative stimuli induce persistent $\mathrm{ADF} /$ cofilin-actin rods that disrupt distal neurite function. Nat Cell Biol 2:628-636.

Oddo S, Caccamo A, Shepherd JD, Murphy MP, Golde TE, Kayed R, Metherate R, Mattson MP, Akbari Y, LaFerla FM (2003) Triple-transgenic model of Alzheimer's disease with plaques and tangles: intracellular A $\beta$ and synaptic dysfunction. Neuron 39:409-421.

Perez RG, Zheng H, Van der Ploeg LH, Koo EH (1997) The $\beta$-amyloid precursor protein of Alzheimer's disease enhances neuron viability and modulates neuronal polarity. J Neurosci 17:9407-9414.

Phinney AL, Deller T, Stalder M, Calhoun ME, Frotscher M, Sommer B, Staufenbiel M, Jucker M (1999) Cerebral amyloid induces aberrant axonal sprouting and ectopic terminal formation in amyloid precursor protein transgenic mice. J Neurosci 19:8552-8559.

Pike CJ, Burduick D, Walancewicz A, Glabe CG, Cotman CW (1991) In vitro aging of beta amyloid protein causes peptide aggregation and neurotoxicity. Brain Res 563:311-314.

Proschel C, Blouin M-I, Gutowski N, Ludwig R, Noble M (1995) LIMK1 is predominantly expressed in neural tissue and phosphorylates serine threonine and tyrosine residues in vitro. Oncogene 11:1271-1281.

Rosso S, Bollati F, Bisbal M, Peretti D, Sumi T, Nakamura T, Quiroga S, Ferreira A, Cáceres A (2004) LIMK1 regulates Golgi dynamics, traffic of Golgi-derived vesicles, and process extension in primary cultured neurons. Mol Biol Cell 15:3433-3449.

Sabo S, Lambert MP, Kessey K, Wade W, Krafft G, Klein WL (1995) Interaction of beta-amyloid peptides with integrin in a human nerve cell line. Neurosci Lett 184:25-28.

Sabo SL, Ikin AF, Buxbaum J, Greengard P (2001a) The Alzheimer amyloid precursor protein (APP) and FE65, an APP-binding protein, regulate cell movement. J Cell Biol 153:1403-1414.

Sabo SL, Ikin AF, Buxbaum J, Greengard P (2001b) The Alzheimer amyloid precursor protein (APP) and its regulatory protein, FE65, in growth cones and synapses in vitro and in vivo. J Neurosci 23:5407-5415.

Saporito-Irwin SM, Van Nostrand WE (1995) Coagulation factor XIa cleaves the RHDS sequence and abolishes the cell adhesive properties of the amyloid beta-protein. J Biol Chem 270:26265-26269.

Spires TL, Hyman BT (2004) Neuronal structure is altered by amyloid plaques. Rev Neurosci 15:267-278.

Stern EA, Bacskai BJ, Hickey GA, Attenello FJ, Lombardo JA, Hyman BT (2004) Cortical synaptic integration in vitro is disrupted by amyloid- $\beta$ plaques. J Neurosci 24:4535-4540. 
Storey E, Beyreuther K, Masters CL (1996) Alzheimer's disease amyloid precursor protein on the surface of cortical neurons in primary culture colocalizes with adhesion patch components. Brain Res 735:217-231.

Sumi T, Matsumoto K, Takai Y, Nakamura T (1999) Cofilin phosphorylation and actin cytoskeletal dynamics regulated by Rho- and Cdc42activated LIM-kinase 2. J Cell Biol 147:1519-1532.

Thal DR, Udo R, Orantes M, Braak H (2002) Phases of A $\beta$-deposition in the human brain and its relevance for the development of AD. Neurology 58:1791-1800.

Tsai J, Grutzendler J, Duff K, Gan W-B (2004) Fibrillar amyloid deposition leads to local synaptic abnormalities and breakage of neuronal branches. Nat Neurosci 7:1181-1183.

Turner CE (2000) Paxillin interactions. J Cell Sci 113:4139-4140.

Van Nostrand WE, Melchor J, Keane D, Saporito-Irwin S, Romanov G Davis J, Xu F (2002) Localization of a fibrillar amyloid $\beta$-protein binding domain on its precursor. J Biol Chem 277:36392-36398.
Yamazaki T, Koo EH, Selkoe DJ (1997) Cell surface amyloid $\beta$-protein precursor colocalizes with $\beta 1$ integrins at substrate contact sites in neural cells. J Neurosci 17:1004-1010.

Yankner BA, Duffy LK, Kirschner DA (1990) Neurotrophic and neurotoxic effects of amyloid beta protein: reversal by tachykinin neuropeptides. Science 250:279-282.

Yuan J, Yankner BA (2000) Apoptosis in the nervous system. Nature 407:802-809.

Zambrano N, Bruni P, Minopoli G, Mosca R, Molino D, Russo C, Schettini G, Sudol M, Russo T (2001) The beta-amyloid precursor protein APP is tyrosine-phosphorylated in cells expressing a constitutively active form of the Abl protoncogene. J Biol Chem 276:19787-19792.

Zhao L, Ma QL, Calon F, Harris-White ME, Yang F, Lim GP, Morihara T, Ubeda OJ, Ambegaokar S, Hansen JE, Weisbart RH, Teter B, Frautschy SA, Cole GM. (2006) Role of p21-activated kinase pathway defects in the cognitive deficits of Alzheimer disease. Nat Neurosci 9:234-242. 